\title{
Benchmarking Logistics Facilities: A Rating Model to Assess Building Quality and Functionality
}

\begin{abstract}
Purpose - Logistics real estate has been experiencing a recent rebirth led by the growth of retailing and e-commerce. Although these sectors are looking for facilities that match their logistics needs, the identification of the most suitable building might become a challenging task. To date, from both the practitioner's and academic perspectives there is a lack of models for assessing the quality of logistics facilities together with their functionality (i.e. whether a warehouse is suitable for hosting a given logistics activity). The aim of this paper is to fill this gap by developing a rating model for assessing the quality and functionality of logistics facilities.

Design/methodology/approach - A three-pronged methodology was adopted. First, a Systematic Literature Network Analysis (SLNA) was carried out to identify the relevant features that must be taken into consideration when assessing logistics real estate. Second, a Delphi method involving experts in the field was used to fine-tune the list of features that emerged from the SLNA process and to evaluate the importance of each feature from a company perspective. The rating model was developed and validated through pilot tests on 27 logistics facilities.

Findings - The rating model is divided into four sections: location, technical specifications, external spaces and internal areas. As an output, the model determines the building quality and main functionality, together with a gap analysis to detect the weakest emerging elements.

Originality/value - This research fills an identified research gap in the logistics real estate literature. Specifically, it offers a quantitative and shared evaluation method, which can be used to estimate building quality and functionality, thus extending the scope of the previous assessment methods available.
\end{abstract}

Keywords: Rating system, logistics facility, warehouse, cross-docking facility, building performance measurement, benchmarking. 


\section{Introduction}

Logistics real estate has been experiencing a recent revival, induced by the numerous transformations to the logistics landscape. Several reasons behind this significant growth may be identified.

First, investments in logistics real estate have risen exponentially in Europe, with a 9\% increase in logistics take-up for warehouses over 5,000 square metres in size (BNP Paribas Real Estate, 2018). In Italy, the phenomenon is still in its early stages and is already showing growth. In 2017, the take-up levels were led by third-party logistics (3PL) providers (45\% of the total take-up), retailers (22\%) and e-commerce companies (17\%). The number of transactions (contracts and financial transactions) concerning new constructions is now higher than for existing buildings (61\% versus $39 \%$, with a reversal of the historical trend having taken place in 2017. The growth of this industry is also proven by the vacancy rate (the number of empty facilities available on the market), which has been reduced by half since 2013 (GVA Redilco, 2018).

Second, changes to the logistics and manufacturing sectors have contributed towards refocusing the attention on logistics real estate. On one hand, an increase in demand for logistics outsourcing services has been detected; today 3PLs need to satisfy their customers' operating requirements and ever-growing demand for quality (Raut et al., 2018). On the other hand, Industry 4.0 and the new regulations necessary in global supply chains have been demanding building innovations (Dablanc and Ross, 2012). As such, logistics facilities have been evolving gradually from conventional buildings fitted out with pallet racks and forklift trucks to more complex buildings equipped with technological devices. Aspects such as provisions for technological equipment, the presence of firefighting and/or green systems and specific layout features are now a fundamental part of establishing whether or not a warehouse is a top-class logistics facility (Aljohani et al., 2016).

In this evolving landscape, assessing a logistics facility on the basis of its size (e.g. in terms of floor area) and a few other aspects, without resorting to a more structured holistic model, inevitably curtails the analysis (Mattarocci and Pekdemir, 2017; Rouwenhorst et al., 2000). Therefore, a growing need has emerged to come up with more sophisticated rating systems that are able to measure both the building's architectural and equipment features - that is to say the building 'quality' - at the same time as its compliance with logistics operating requirements, in other words, building 'functionality'.

The topic of logistics real estate assessment has been skimmed over in the academic literature so far. The main focus has essentially been on the development of assessment models to measure the building marketability through financial indicators (French and Gabrielli 2004; Pagourtzi et al., 2003), on rating models to evaluate sustainability features (Mattoni et al., 2018; Berardi, 2012), or on models for logistics land use, aiming to identify suitable locations where warehouses should ultimately be built (Hesse, 2004). This lack of a comprehensive model that can provide a structured and holistic assessment of logistics facilities is significant, since the value of a building is not merely linked to financial metrics or its individual features (e.g. size or the clear building 
height), and it must take into consideration multiple elements simultaneously, together with its operating requirements (Ma et al., 2018).

Given these premises, the present paper aims to fill the gap highlighted by developing a rating model for assessing the quality and functionality of logistics facilities. To ensure both robustness and practical effectiveness, the model builds on the analysis of the extant literature on logistics real estate and also includes the managers' perspective thanks to the participation of a pool of ten experts selected from among real estate agents, property developers, investors and fund managers.

From the perspective of functionality, the model focuses on two distinct types of buildings, namely stock warehouses and cross-docking facilities, as they are defined in literature as the most common facilities in the logistics sector (Staudt et al., 2015; Baker and Canessa, 2009) and they have different functions and related implications for inventory and customer lead times, as well as for costs and service (Baker, 2004).

The model is structured into four main sections - namely 'Location', 'External areas', 'Technical equipment' and 'Internal spaces' - with 50 features being assessed overall. The building quality is expressed as a number of stars (from 1 to 5 ) and is given by the sum of the scores assigned to the options selected for each individual feature. The building functionality is measured as a percentage out of total of $100 \%$ based on the number and type of features being selected that characterise either warehouses or cross-docking facilities.

The remainder of the paper is organised as follows. The next section includes a review of the rating models currently available in the real estate literature, as well as the relevant features to be considered when assessing logistics real estate. The research questions are described in Section 3, whereas the methodologies adopted are described in Section 4. The rating model formulation is then presented, together with the model validation process, followed by the discussion and conclusions, with recommendations for further studies in the field.

\section{Literature review}

\subsection{Rating models in the real estate industry}

In the real estate industry, assessment and/or rating models are widely used to evaluate the marketability of residential buildings, offices, industrial buildings and other kinds of building (Mattarocci and Pekdemir, 2017). Rating is necessary to reduce uncertainty about the value of a property and, for valuers, can establish the credibility for their work on behalf of their customers (French, 2004).

The real estate value chain includes several players, such as real estate agents, appraisers, assessors, mortgage lenders, brokers, property developers, investors and fund managers, lenders, market researchers and analysts, building tenants, and others (Pagourtzi et al., 2003). Many of them may be involved in the evaluation of a building, and the right decision or most cost-effective investment can hinge on this process. 
The real estate industry has been widely studied by financial scholars since the evaluation of real estate markets is strictly related to financial decisions (e.g. mortgages, taxes, investment portfolio) and to other macro-economic elements, such as employment rate, population gross income, and levels of social living (Northcraft et al., 1987; Kaklauskas et al., 2007; Ginevičius and Zubrecovas, 2009). Therefore, rating models - intended as systems for evaluating and classifying the investment risk - have been applied also to the real estate market (Renigier-Biłozor et al., 2014). However, as discussed by Wyman et al. (2011), the real estate market differs from the stock market, since the former deals with durable highly differentiated long-term assets located at a specific site. Therefore, decisions about building value require a more thorough understanding, based not merely on economic factors, but also on other qualitative features belonging to the asset itself (Turskis et al., 2009).

The need for rating real estate buildings has become even more important since 2002, when the European Commission issued the Energy Performance of Buildings Directive (2002/91/EC) requiring member states to introduce energy assessment and building certification methods (Asdrubali et al., 2015). Given the institutional pressure to increase the environmental performance of buildings (Zimmermann et al., 2005), greater attention is now being paid to environmental assessment matters, leading to the development of several building rating models, known as Green Building Rating Systems (GBRS). These models have been introduced within the construction industry to assess a building's degree of sustainability, and the most significant are recognised as international standards. These include LEED (Leadership in Energy and Environmental Design), BREEAM (Building Research Establishment Environmental Assessment Method), Green Star, Green Globes, SBTool, and several national protocols such as DNGB (Deutsche Gesellschaft für Nachhaltiges Bauen) for Germany and ITACA (Istituto per l'Innovazione e Trasparenza degli Appalti e la Compatibilità Ambientale) for Italy (Mattoni et al., 2018; Todd et al., 2013; Berardi, 2011; Marsh et al., 1996). However, these models were designed for residential or industrial buildings rather than specifically for logistics facilities. Some adjustments can be made to fit these models into the logistics context and requirements, but their focus is more on merely assessing the building environmentally, through aspects such as limiting gas emissions, energy consumption and applying green rules during the building design and construction (Ding, 2008; Ugwu and Haupt, 2007).

\subsection{Rating models for assessing logistics facilities}

As mentioned above, the literature analysis has revealed that some rating models measuring sustainability issues originally developed for residential and/or industrial buildings can be adapted and applied to logistics facilities. So far, however, there has been little investigation into the development of ad hoc rating models designed specifically for the logistics real estate industry.

An example comes from Buttimer et al. (1997), who explored the determinants of industrial warehouse rental prices in the U.S.A., within the Dallas/Fort Worth area. They built their work on 
previous research by Ambrose (1990), whose model for deciding warehouse rents took into account the physical properties of a building. Buttimer et al. (1997), on the contrary, used a panel data model to analyse cross-sectional and time-series data, since studies have shown that industrial rents are a function of both time-invariant characteristics (the building physical features), and time-varying characteristics (such as market vacancy rates). Rent value is determined through a series of variables, consisting of gross rentable square footage, ceiling height, percentage of office space, number of years since its construction, number of loading bays, distance from nearest freight railway yard, presence of a sprinkler system, market vacancy rate (submarket occupancy) and market conditions. Results indicate that rents are significantly impacted by the warehouse physical characteristics and its location, as well as the general market conditions.

Oh and Shin (2016) provide another interesting model, focusing on the determinants of warehouse rental prices. In this case, the data refer to South Korea and the model considers a number of aspects, including location-related information (area/province; access to ports, major cities and the motorway system; width of adjacent streets), building specifications (floor area, plot size, number of parking spaces per plot size, ceiling height, building age, cold and frozen storage facilities, conglomerate tenant) and macro-environment issues (e.g. gross regional domestic product for the region, employment to population ratio). The study shows that warehouse rent is affected mainly by its transport accessibility, while macro-environmental variables do not seem to affect rent by any significant measure.

On a similar scope, Ma et al. (2018) applied machine learning algorithms (linear regression, regression tree, random forest regression and gradient boosting regression trees) to estimate warehouse rental prices in China, within the Beijing area. The data collected mostly referred to information about location (e.g. district, latitude, longitude, distance from city centre and distance from the nearest house), the size of the logistics building and local house prices. Based on their study, the authors claim that a multiple factor model can estimate rental pricing better than a single factor model, such as linear regression. In their conclusion, they suggest including additional features to estimate the warehouse value more comprehensively. Finally, Mattarocci and Pekdemir (2017) carried out a detailed study on logistics real estate investments. Their work is particularly interesting as it points out the main features of logistics real estate in Europe, and they bring in new features when assessing a logistics facility. They introduced the concept of 'purpose of usage' to capture the complexity and diversity of logistics buildings. In line with the above studies, Mattarocci and Pekdemir also provided an extensive analysis of the facility location. In their work, they focused on the following features: proximity (to customers, suppliers, carrier hubs), matters relating to labour and government (availability and flexibility of labour, labour costs, regulatory issues and incentives), real estate (real estate costs, availability of land, availability of existing modern warehouses), infrastructure (proximity to economic networks, proximity and quality of road access and proximity to various transport modes, transport costs). In addition, they defined other relevant attributes, such as age, size (total floor space), type of 
loading bays (for trucks and lorries), 360-degree circulation around the building, cross-docking configuration and car/truck parking.

In most cases, the models analysed in the extant literature do not provide a holistic evaluation of the logistics facility and they do not assess its main functionality, or, in other cases, they focus on specific facets or features relating to the building itself.

\subsection{Relevant features for evaluating the quality of logistics real estate}

Within both the real estate and the logistics literature, a number of features have emerged as relevant in the assessment of the quality of an industrial and/or logistics facility. The concept of 'quality' is strictly related to the 'value' of the building (Levitt and Syverson, 2008). Quality is not only of a combination of architectural and physical characteristics (Case and Quigley, 1991), but it is also a set of features that affect the overall evaluation of the building (such as site location, external spaces, the building technical specifications, internal areas, utilities and 'green systems'). Table 1 lists the holistically relevant features that were highlighted in the literature, clustered into five main areas:

- location surroundings and connections;

- external spaces;

- technical/construction specifications;

- internal areas, utilities and 'green systems';

- management and maintenance costs.

\section{XXXXXXXXXXXXXXXXXXXXXXXXXXXXXXXXXXXXXXXXXXXXXXXXXXXXXXXXXXXXXXXXXXXXXXXXX} Insert Table 1

\section{XXXXXXXXXXXXXXXXXXXXXXXXXXXXXXXXXXXXXXXXXXXXXXXXXXXXXXXXXXXXXXXXXXXXXXXXX}

According to Ma et al. (2018) and Diziain et al. (2014), location is one of the most important features in real estate, and it has also been investigated extensively in the logistics field. With respect to logistics facilities, location is seen as key to an efficient distribution network (Dablanc and Ross, 2012; McKinnon, 2009), and its elements can include the specific site location (in terms of latitude and longitude, as well as its municipality/district/region), the transport services and infrastructure available in the surroundings, such as motorways, railway stations, ports and airports as well as proximity to logistics centres and freight villages (Oláh et al., 2018; LipińskaSłota and Mindur, 2018) or to customers and suppliers. The location of a logistics building can increase its value if it is an asset to the logistics operations (Woudsma, 2008). For instance, a warehouse near a motorway can deliver goods faster than a more distant facility. The value given to the location can also depend on the actual building function. For instance, central warehouses and last mile cross-docking facilities often have different location needs (Mattarocci and Pekdemir, 2017; Dablanc and Ross, 2012), meaning that the location can take on various roles. 
The external spaces are the areas and arrangements for docking the trucks (e.g. truck parking lots, number of loading bays, dock levellers and loading bay safety equipment). These are important as they can affect how warehouse performance is measured. For instance, the number of loading bays comes into play when measuring warehouse inbound productivity (Staudt et al., 2015).

Technical and construction specifications refer to factors such as the building plot, layout, floor space, clear building height, structural mesh and roof structure (Ciaramella, 2010).

The internal areas can be areas used for recharging material handling equipment, the offices and refrigeration rooms. In this perspective, utilities are also relevant, and cover a range of equipment and appliances, such as fire-detecting and fire-fighting systems, lighting systems, electric systems, heating/air-conditioning systems and photovoltaic systems (Oh and Shin, 2016; Ciaramella, 2010; Pagourtzi et al., 2003; He et al., 2002). Sustainability aspects also come into the equation and are normally included in building sustainability certifications (Mattoni et al., 2018).

Lastly, management and maintenance costs refer mainly to costs for covering building and system maintenance, but they can include costs relating to innovative systems, such as the Building Management System (BMS), which control and manage the entire building efficiently from either a sustainability or a cost-based perspective (De Marco et al., 2010).

Apart from the above-reported features, the purpose of usage (a building 'functionality') seems to have been generally neglected in previous literature, despite being such an important factor for assessing a logistics facility. In line with Mattarocci and Pekdemir (2017), the functionality of a logistics facility indicates whether - and how closely - the building is 'fit for purpose'. In other words, functionality indicates whether a logistics building is suitable for hosting a certain type of logistics operations (e.g. storage, picking and sorting). It is clear that logistics facilities can have different functions, with the most common being to hold stock (Staudt et al., 2015), as in the case of a conventional stock warehouse, where goods are stored in racks and customer orders are assembled before delivery. A second function is that of cross-docking, where goods are moved directly from the receiving area of a warehouse to the shipping area, rapidly sorted and loaded ready for their onward journey (Agustina et al., 2014; Baker and Canessa, 2009; Kreng and Chen, 2008). According to Baker and Canessa (2009), logistics facilities can take on other secondary functions, including value added services (e.g. secondary packaging activities and labelling) and production postponement (where the final assembly takes place on the basis of the customers' orders, so the warehouse only needs to stock generic products), returned goods (for reverse logistics) and other operations, such as servicing and repair work.

Although the potential area of interest is extensive, there is so far a lack of models involving a number of related features used to evaluate a logistics facility, in terms of its quality and its compatibility with that given function (i.e. functionality).

\section{Research questions}

The literature examined revealed no logistics real estate assessment models with a specific focus on building quality and functionality. The present research aims to fill this research gap by 
developing a rating model for evaluating logistics real estate, which can identify, classify and rate the most relevant features of a logistics facility. The intended objective is to assess the overall facility quality, while also identifying its main functionality. From this latter perspective, the model focuses on two distinctive types of buildings, namely stock warehouses and cross-docking facilities, as they are defined in literature as the most common facilities in the logistics sector (Staudt et al., 2015; Baker and Canessa, 2009) and they have different functions and related implications for inventory and customer lead times, as well as for costs and service (Baker, 2004). In its current version, the rating model was developed to be suitable for the Italian context. The interest in focussing on the Italian logistics real estate is motivated by several factors. First, Italy is one of the countries experiencing a recent and significant renaissance in the logistics real estate sector (GVA Redilco, 2018). Second, it is generally recognised that warehouse location is one of the most important and strategic decisions in the optimisation of logistics systems (McKinnon, 2009). This is particularly true for Italy, where the country geographical peculiarities need to be taken into account, making this case especially worthy of investigation (Battezzati and Magnani, 2000). As such, some limitations specific to the Italian context have been brought in intentionally (e.g. constraints in regulations, geographical features and logistics requirements).

According to the objectives defined above, the following research questions (RQs) have been identified:

- RQ1: What are the main distinctive features of warehouses and cross-docking facilities in Italy from a real estate perspective?

- RQ2: What are the relevant features to be considered when assessing a logistics facility?

- RQ3: How do these features contribute to the evaluation of overall quality and functionality for the logistics facility under assessment?

\section{Methodology}

The research methodology was divided into three main phases, as shown in Figure 1.

\section{XXXXXXXXXXXXXXXXXXXXXXXXXXXXXXXXXXXXXXXXXXXXXXXXXXXXXXXXXXXXXXXXXXXXXXXXX Insert Figure 1 XXXXXXXXXXXXXXXXXXXXXXXXXXXXXXXXXXXXXXXXXXXXXXXXXXXXXXXXXXXXXXXXXXXXXXXXX}

In Phase 1, a Systematic Literature Network Analysis (SLNA) was performed on a cluster of 153 peer-reviewed journal papers. According to the SLNA approach (Colicchia and Strozzi, 2012), a Systematic Literature Review (SLR) (Rousseau et al., 2008; Tranfield et al., 2003) was initially required to conduct a first selection of the most relevant papers, followed by a Citation Network Analysis (CNA) (Hummon and Doreian, 1989) to investigate the process of knowledge creation, transfer and development. The scope of the analysis was to study the rating models available in the real estate industry. Specifically, as the unit of analysis for this research was the logistics facility, a particular focus was on logistics buildings, and on the relevant features that must be 
considered when assessing a logistics facility. The keywords identified (such as 'real estate', 'building', 'rating', 'evaluation', 'warehouse', 'logistics', ‘design' and 'location') and the associated combinations were used as search terms in Scopus, which is one of the scholar citation databases most commonly used for field delineation (Strozzi et al., 2017). The selection criteria stipulated that the papers had to be written in English, that the source consisted of journals, conference proceedings and book chapters, and that the subject areas were engineering and management. In line with Strozzi et al. (2017), a series of 'milestone' papers were further added to improve the level of comprehension regarding the literature review. The selected papers were finally analysed using a bibliographic network analysis tool, VOSviewer, chosen because it can work efficiently with large data sets and provide a range of innovative visualisation, analysis and investigation options (Fahimnia et al., 2015). As an example, Figure 2 gives the outcome of the keyword co-occurrence network analysis.

The main themes that emerged from the SLNA process were recorded and discussed previously in the Literature Review section.

\section{XXXXXXXXXXXXXXXXXXXXXXXXXXXXXXXXXXXXXXXXXXXXXXXXXXXXXXXXXXXXXXXXXXXXXXXXX} Insert Figure 2

\section{XXXXXXXXXXXXXXXXXXXXXXXXXXXXXXXXXXXXXXXXXXXXXXXXXXXXXXXXXXXXXXXXXXXXXXXXX}

In Phase 2 (Gathering the experts' opinions), the list of features emerging from the SLNA process was checked through a Delphi method (Dalkey and Helmer, 1963), which was also used to evaluate the importance of each feature from a practitioners' perspective. This method has been previously used by other scholars studying the real estate industry in order to prioritise the criteria for evaluating buildings (Glumac et al., 2011; Pivo, 2008). For the purposes of this study, a pool of ten experts were selected from among real estate agents, property developers, investors and fund managers operating in Italy, in line with the focus of the RQs. Consistently with Ndour et al. (1992), these experts were selected on the basis of three criteria: (1) experience in the logistics real estate market (i.e. working in a company operating in the logistics real estate value chain), (2) representation of different viewpoints (i.e. they needed to be professionals involved in projects regarding the construction or sale of warehouses and/or cross-docking facilities) and (3) thorough knowledge of the industry in Italy (i.e. more than 10 years' experience in the logistics real estate sector). Overall, the pool of experts eventually included:

- investors: two experts, i.e. a Country Manager and an Asset Management Director, both with more than 20 years' experience in the sector;

- property managers: one expert, i.e. head of the Logistics Department with more than 10 years' experience;

- real estate agents: one expert, i.e. Managing Director with more than 10 years' experience;

- multinational property developers: three experts, i.e. a Country Manager (more than 15 years' experience), a Technical Director (more than 10 years' experience) and a Managing Director (more than 20 years' experience); 
- construction companies: three experts, i.e. a Project Manager (more than 10 years' experience) and two Chief Executive Officers (both with more than 30 years' experience).

Five further practitioners were added to the pool of experts, with a background in producing or selling specific types of warehouse equipment, such as fire-fighting systems, lighting systems, loading bays and racks, so that they were able to provide a detailed assessment of utilities and 'green' systems.

The Delphi method consisted in a number of stages. First, the pool of experts held a brainstorming meeting to validate and complete the list of features and relevant areas (location, external spaces, technical specifications of the building, internal areas, utilities and 'green systems') discovered during the SLNA process. The experts were asked to add to, modify and approve the list of features derived from the literature. They were also asked to rank the four areas identified by assigning a weight to each, as a percentage from 0 - least relevant - to 100 most relevant - based on their impact on the overall rating of the logistics facility. In addition to the four identified areas, several sub-areas ('context', 'proximity to transport infrastructures', 'external yard', 'loading/unloading bays', 'building size', 'structure', 'offices and other spaces' and 'utilities and green systems') were similarly given weights in percentage values.

At this stage all the experts agreed about the two main types of logistics building identified in the SLNA, i.e. warehouses, mainly used for storage and picking operations, and cross-docking facilities, with sorting and shipping as the prevailing activities. To take into account the two possible functions of the logistics building during the assessment, two different outputs were asked for at this stage, i.e. weights related to each area in the case of a warehouse and weights related to each area in the case of a cross-docking facility.

It should be noted that all the experts identified a set of distinguishing features for warehouses and cross-docking facilities. The resulting ten distinguishing features for warehouses and the ten for cross-docking facilities are given in Table 2.

\section{XXXXXXXXXXXXXXXXXXXXXXXXXXXXXXXXXXXXXXXXXXXXXXXXXXXXXXXXXXXXXXXXXXXXXXXXX}

Insert Table 2

\section{XXXXXXXXXXXXXXXXXXXXXXXXXXXXXXXXXXXXXXXXXXXXXXXXXXXXXXXXXXXXXXXXXXXXXXXXX}

The completed list of relevant features was sent to all the experts individually, asking them to rank the features in each area by allocating a percentage weight based upon the impact of each on their associated area, with the total for each area being $100 \%$. The resulting weights were then collected and normalised by re-scaling the values according to the number of features in each area. At this point, a Pareto analysis (Kefer et al., 2016) was performed to display all the features ranked according to their assigned weight (from the highest to the lowest) and identify the most significant. Through this analysis it was possible to identify the features that had greatest influence over the output of the model. As an example, for cross-docking facilities, the evaluation seemed influenced mostly by the facility distance from the motorway, by the number of loading docks and by the size of the external area. Regarding warehouses, the evaluation seemed highly 
dependent on the year in which the building was constructed, its clear height, the type of firefighting system in place and the building floor load. Data were then analysed and shared with the experts. At this stage, the purpose was to reach a consensus (Okoli and Pawlowski, 2004) about the assigned weights, eventually leading to the final list of relevant features, each with its associated weight.

A five-star rating model was finally developed in Phase 3. This rating method was selected because the metrics are easy to understand and identify (Sparling and Sen, 2011). Five-star ratings are widely deployed in many fields of research, including finance, hotels, quality of information, ecommerce and car safety assessment programmes (Flanagin et al., 2014; Coval et al., 2009; Mannion et al., 2005; Israeli, 2002) and are also considered suitable for assessing sustainabilityrelated performance in real estate (Berardi, 2011).

As a result, the model was structured into four sections corresponding to the areas identified by the experts (location, surroundings and connections, external spaces, technical specifications of building, internal areas, utilities and green systems), each divided into sub-sections. The details of how the model was formulated are given in Section 5.

Lastly, the rating model was validated through pilot tests on 27 existing logistics facilities, chosen with the support of the experts. Specifically, experts helped identify a number of logistics buildings from their portfolios. Among those, buildings were then selected with different characteristics in terms of:

1) Size: more than $40,000 \mathrm{~m}^{2}$ (5 facilities), between 10,000 and $40,000 \mathrm{~m}^{2}$ ( 8 facilities), and less than 10,000 $\mathrm{m}^{2}$ (14 facilities).

2) Clear building height: more than $9 \mathrm{~m}$ (11 facilities), less than $6 \mathrm{~m}$ (4 facilities), and between 9 and $6 \mathrm{~m}$ (12 facilities).

3) Average loading/unloading bay density [No. bays $/ \mathrm{m}^{2}$ ]: more than $1 / 800$ bays $/ \mathrm{m}^{2}$ (11 facilities), between $1 / 800$ and $1 / 200$ bays $/ \mathrm{m}^{2}$ (11 facilities), and less than $1 / 200 \mathrm{bays} / \mathrm{m}^{2}$ ( 5 facilities).

4) Year of construction: from 2018 to 1963 with a focus on recent facilities.

Semi-structured interviews and on-site visits were conducted to collect the data necessary to run the model, with the interviewees being the tenants and/or owners of logistics facilities located in Italy and operating in various industry sectors (fast-moving consumer goods (FMCG), 3PLs providers and couriers). All the structured interviews were carried out in line with the method used by Villena (2019). Specifically, as for Villena, the researchers shared the model with the interviewees in advance in order to have all the information available during the meeting. The researchers offered anonymity to each interviewee to encourage open discussion and assured the participants that detailed information would not be shared unless in aggregated form. The results of the interviews were recorded, transcribed, and the data collected were sent for final approval. This stage helped pinpoint the areas where to make corrections to the five-star rating model, adjustments to the wording, as well as providing the first results of the rating procedure.

\section{Model Formulation}




\subsection{Model Structure and Weights}

The rating model interface contains three hierarchical levels: sections, sub-sections and individual features, with one-choice options for each feature, as per Figure 3.

XXXXXXXXXXXXXXXXXXXXXXXXXXXXXXXXXXXXXXXXXXXXXXXXXXXXXXXXXXXXXXXXXXXXXXXXX Insert Figure 3

\section{XXXXXXXXXXXXXXXXXXXXXXXXXXXXXXXXXXXXXXXXXXXXXXXXXXXXXXXXXXXXXXXXXXXXXXXXX}

The sections reflect the main clusters of features derived from the literature review and the panel of experts, namely:

- Section 0, general information about the building, such as the tenant, province, municipality, year of construction, size of building plot $\left(\mathrm{m}^{2}\right)$, total floor space $\left(\mathrm{m}^{2}\right)$, gross office floor space, clear building height (m) and number of loading bays;

- Section 1: 'Location, surroundings and connections'

- Section 2: 'External spaces'

- Section 3: 'Technical specifications of building'

- Section 4: 'Internal areas, utilities and green systems'

'Management and maintenance costs' a feature revealed by the SLNA process, was not chosen as a model section for a number of reasons. In any building, there is an intrinsic link between the item 'management and maintenance costs' and some of its properties - age, functionality, location and size (El-Haram and Horner, 2002) - meaning that they cannot be considered as additional independent factors to be assessed. In addition, there are costs for management and maintenance associated to the internal equipment/systems used by the facility tenants in the course of their activity, and these systems are not necessarily linked to the quality or functionality of the facility itself (De Marco et al., 2010). For instance, the implementation of automated material handling solutions can easily be associated to higher maintenance costs (De Marco and Mangano, 2011), although they are not necessarily permanent, and are not part of the fabric of the building. In order to take maintenance matters into consideration, it was decided that the rating model must look at whether the facility has a Building Management System (BMS).

The four sections are divided into the following specific subsections, as per Table 3. Every subsection is associated to a list of related features, each with several one-choice options. To minimise the time needed to input data, the procedure has a number of 'hidden features' which the model elaborates automatically on the basis of the options selected when completing the other sections/features (such as the ratio between number of loading bays and the floor space, and that between floor space and the size of the building plot). 
Insert Table 3

XXXXXXXXXXXXXXXXXXXXXXXXXXXXXXXXXXXXXXXXXXXXXXXXXXXXXXXXXXXXXXXXXXXXXXXXX

As illustrated in the section on Methodology, the weights defined in Phase 2 set out the importance of each section and its associated features in the overall evaluation. The weights are assigned to the various sections and individual features in accordance with the experts' reckoning, as deduced from the Delphi method. Table 4 sets out the weights assigned to each section for warehouses and cross-docking facilities.

\section{XXXXXXXXXXXXXXXXXXXXXXXXXXXXXXXXXXXXXXXXXXXXXXXXXXXXXXXXXXXXXXXXXXXXXXXXX} Insert Table 4

\section{XXXXXXXXXXXXXXXXXXXXXXXXXXXXXXXXXXXXXXXXXXXXXXXXXXXXXXXXXXXXXXXXXXXXXXXXX}

When assessing each feature, the weight for each individual option is defined according to a parametric scale, so that the 'best' option receives the 'maximum' weight and the other options are given a quota of that weight, calculated according to a linear pattern. For instance, for the feature 'distance from the nearest motorway entrance', there are four possible options, 'less than $5 \mathrm{~km}$ ', 'between 5 and 15 km', 'between 15 and $30 \mathrm{~km}$ ' and 'more than $30 \mathrm{~km}$ '. The best option (in this case, 'less than $5 \mathrm{~km}$ ') is given the highest value (4 out of 4 , which is the maximum weight), while the other choices are given a quota of that value, following a linear trend. The further the logistics facility is from the motorway entrance, the lower is the value assigned to that option. This means that the next option, 'between $5 \mathrm{~km}$ and $15 \mathrm{~km}$ ', is given $3 / 4$ of the maximum weight, the next one, 'between $15 \mathrm{~km}-30 \mathrm{~km}$ ', is given 2/4 of the maximum value and the last option, 'more than 30 $\mathrm{km}$ ', is given $1 / 4$ of the maximum weight. It can be the case that the worst option corresponds to zero, when the feature examined is 'absent' (e.g. no BMS system).

\subsection{Model Inputs and Main Outputs}

Taking a given logistics facility, the input to the model is:

- general data about the building, as per Section 0;

- one option selected for each feature from each of the four sections ('location, surroundings and connections', 'external spaces', 'technical specifications of building', and 'internal areas, utilities and green systems').

Based on the input, the model produces four different outputs:

- the prevailing functionality of the logistics facility, in percentages (for example, 75\% warehouse, or $83 \%$ cross-docking facility), based on the number and types of the distinguishing features selected that are associated to warehouses or cross-docking facilities, as discussed previously and presented in Table 2; 
- the overall quality of the building expressed in the number of stars (1 to 5), calculated by adding together all the scores associated to the various features and relative options selected;

- the quality scores for each section, in percentages (e.g. 59\% for 'location, surroundings and connections', 75\% for 'external spaces', 85\% for 'technical specification of building' and 65\% for 'internal areas, utilities and green systems');

- the list of 10 weakest elements that emerged from the gap analysis (for each section, calculated as the difference between the weight of the selected options and the 'best' options available).

When no clear primary functionality appears from the model results, the facility is defined as 'hybrid' and the quality outcomes for the two functionalities (stock warehouses and cross-docking facilities) are recorded separately.

Lastly, as an interesting footnote to the last output (the 10 weakest elements emerging from the assessment), the gap analysis offers a very useful tool for identifying potential directions for future improvements to the overall building quality, also depending on the building functionality.

\subsection{Model Validation}

The rating model was validated through pilot tests on 27 existing logistics facilities located in Italy. As anticipated, the buildings were selected according to their different characteristics - in terms of year of construction, size, geographical location, building specifications and utilities and the different industry sectors in which they operated (fast moving consumer goods, food, pharmaceutical and fashion) with different kinds of tenants (manufacturers, retailers, 3PLs and couriers).

Table 5 provides an outline of the 27 logistics facilities included in the pilot test sample. All the companies were promised anonymity.

\section{XXXXXXXXXXXXXXXXXXXXXXXXXXXXXXXXXXXXXXXXXXXXXXXXXXXXXXXXXXXXXXXXXXXXXXXXX}

Insert Table 5

\section{XXXXXXXXXXXXXXXXXXXXXXXXXXXXXXXXXXXXXXXXXXXXXXXXXXXXXXXXXXXXXXXXXXXXXXXXX}

The aim was to include top-class and low-quality buildings in the study. This phase helped set the bands relating to the five-star rating and contributed towards fine-tuning the rating model.

Indeed, in line with the Green Star certification for sustainability (Mattoni et al., 2018), the percentage scores are grouped into bands, and each band is associated to a given number of stars. Initially, the bands were all the same width (same range of percentages), but they were then adjusted. Specifically, the final bands were obtained through an iterative procedure, starting from five bands of the same size (20\% each). The exercise consisted in the above-mentioned 27 pilot tests to take in facilities from either end of the quality spectrum, giving a better feel for the 
suitable band sizes for all the building classes. The resulting five-star rating with their associated bands expressed as percentage values are given in Table 6 .

XXXXXXXXXXXXXXXXXXXXXXXXXXXXXXXXXXXXXXXXXXXXXXXXXXXXXXXXXXXXXXXXXXXXXXXX Insert Table 6

XXXXXXXXXXXXXXXXXXXXXXXXXXXXXXXXXXXXXXXXXXXXXXXXXXXXXXXXXXXXXXXXXXXXXXXXX

At this stage, several features initially included in the model were found not to be useful, and were removed (such as 'fenced building plot' in Section 2, 'external spaces', as it turned that all the facilities examined were fenced and the feature was useless for differentiating purposes).

\section{Discussion and Conclusions}

Although logistics real estate has been the subject of much-renewed interest driven by the numerous transformations taking place in the logistics landscape, as of today the topic of logistics real estate assessment has found very little exposure in academic literature.

The main value of the present research is to fill this gap in literature by presenting a structured and comprehensive rating model to assess the quality and functionality of logistics facilities.

First, starting from the literature review two main types of logistics buildings in Italy have been identified, namely warehouses and cross-docking facilities. For both of them, the distinctive features have been identified, thus addressing RQ1 (What are the main distinctive features of warehouses and cross-docking facilities in Italy from a real estate perspective?). Second, the relevant features to be consider when assessing the quality of both warehouses and cross-docking facilities have been categorised, as per RQ2 (What are the relevant features to be considered when assessing a logistics facility?). Third, specific weights have been assigned to each feature and a comprehensive rating model has been developed to evaluate both quality and functionality of a logistics facility, as per RQ3 (How do these features contribute to the evaluation of overall quality and functionality for the logistics facility under assessment?).

The rating model offers a holistic approach, together with a quantitative method of evaluation, in order to incorporate the perspective of both academics and practitioners. The rating model consists of 4 sections ('location, surroundings and connections', 'external spaces', 'technical specifications of building' and 'internal areas, utilities and green systems'), 8 sub-sections and 50 features and the four different outputs of the procedure are the chief functionalities (the main purpose for which the building is used and expressed as a percentage), the overall quality of a building (which looks at a set of features that affect the overall evaluation of the building, expressed as number of stars), the quality scores for each section (expressed as a percentage) and the 10 weakest elements that cropped up from the assessment. The model was applied to 27 pilot tests, making it possible to pin down the points where corrections and wording adjustments are to be made, as well as to obtain the initial outcome with the first results of the rating procedure. 
This contribution has both academic and practical implications. From an academic perspective, the paper offers interesting insights into the logistics real estate industry, with its analysis of the extant literature and extending the research in this field. In this sense, the results add to previous literature on the topic (Ma et al., 2018; Oh and Shin, 2016, Buttimer et al., 1997), clarifying the concepts of quality (Case and Quigley, 1991) and functionality (Mattarocci and Pekdemir, 2017) in logistics real estate, as well as assessing the two aspects through a structured quantitative tool. This latter point represents one of the major contributions of this research. The proposed rating model overcomes one of the main weaknesses detected in the existing literature, which previously only put forward assessment models where just a few features were examined (Ma et al., 2018; Oh and Shin, 2016, Buttimer et al., 1997). The output was often a partial assessment, focused either on financial indicators (French and Gabrielli 2004; Pagourtzi et al., 2003) or on sustainability type features (Mattoni et al., 2018; Berardi, 2012). The proposed model, on the contrary, offers a comprehensive assessment of a number of relevant features, obtained from both literature and practitioners, and these are evaluated simultaneously. The assessment also takes into account the prevailing building functionality (warehouse versus cross-docking facility), as recommended by Mattarocci and Pekdemir (2017).

From a practical viewpoint, several significant managerial implications in the real estate industry have emerged. First, the proposed rating model can be a valuable tool for all the players operating in the real estate value chain (agencies, appraisers, brokers, property developers, investors, fund managers and logistics service providers), allowing them to identify the correct purpose for which a logistics facility is being used and, therefore, reach a better estimate of the logistics building under assessment. Second, by identifying the building weakest elements, the rating model can also be useful for practitioners in determining the potential areas for improvement in an existing logistics facility. Third, the model can also be used for benchmarking analysis in a specific industry or geographical area. In this case, practitioners can gain an overview of the market and a better understanding of their asset value.

As noted above, this model is a first attempt to explore a research stream that is still underresearched. Although this study produced interesting results and findings, limitations do exist. First, the chosen options and respective weights were set out with reference to the Italian context. Therefore, our model cannot be generalised to other contexts or countries without some adjustments.

Starting from this current version, additional research is recommended to alter some features and adapt the model to other contexts. Second, the functionality of buildings has been analysed by looking only at the two main types of logistics buildings (warehouses and cross-docking facilities). Future studies should consider other types of building, and include other aspects of differentiation, not considered here. Third, the validation of the model was conducted on a small number of pilot tests. A larger dataset of logistics buildings could improve the robustness and validity of the model.

Additional and interesting streams for future investigation can be highlighted. The tenants' perspective could be included, by looking at the features of products stored in the logistics 
buildings (for example pharmaceutical vs. food products requirements). Further relevant features could come into play, such as CO2e emissions for a more thorough focus on sustainability aspects (Marchet et al., 2015; Mangiaracina et al., 2016; Ries et al., 2017), or the cost of warehouse space to include also the economic perspective in the analysis (Onstein et al., 2019). Finally, an interesting benchmarking exercise could be carried out by altering the model and adapting it to the European context and, therefore, studying the differences between Italy and other European countries. Moreover, the model can be used to map logistics facilities within specific geographical areas, with the purpose of creating a database of logistics buildings classified by level of quality and functionality. Extending this viewpoint, data obtained from a larger sample could be used to review and update the distinguishing features of the logistics building types identified in this paper, as well as adjusting their associated weights and scores. Moreover, the use of other methodologies, such as AHP, ANP or TOPSIS, on a subset of the criteria used in the rating model can be taken into account to further improve its robustness (Vieira et al., 2017; Bianchini, 2018). 


\section{References}

Agustina, D., Lee, C. K. M. and Piplani, R. (2014), "Vehicle scheduling and routing at a cross docking center for food supply chains", International Journal of Production Economics, Vol. 152, pp. 29-41.

Aljohani, K., and Thompson, R. G. (2016), "Impacts of logistics sprawl on the urban environment and logistics: Taxonomy and review of literature", Journal of Transport Geography, Vol. 57, pp. 255-263.

Ambrose, B. (1990), "An analysis of the factors affecting light industrial property valuation", Journal of Real Estate Research, Vol. 5 No. 3, pp. 355-370.

Asdrubali, F., Baldinelli, G., Bianchi, F. and Sambuco, S. (2015), “A comparison between environmental sustainability rating systems LEED and ITACA for residential buildings", Building and Environment, Vol. 86, pp. 98-108

Baker, P. (2004). "Aligning distribution centre operations to supply chain strategy". The International Journal of Logistics Management, Vol. 15 No.1, pp. 111-123.

Baker, P. and Canessa, M. (2009), "Warehouse design: A structured approach”. European Journal of Operational Research, Vol. 193 No. 2, pp. 425-436.

Battezzati, L. and Magnani, R. (2000), "Supply chains for FMCG and industrial products in Italy: Practices and the advantages of postponement", International Journal of Physical Distribution \& Logistics Management, Vol. 30 No. 5, pp. 413-424.

Berardi, U. (2011), "Beyond sustainability assessment systems: Upgrading topics by enlarging the scale of assessment", International Journal of Sustainable Building Technology and Urban Development, Vol. 2 No. 4, pp. 276-282.

Berardi, U. (2012), "Sustainability assessment in the construction sector: rating systems and rated buildings”, Sustainable Development, Vol. 20 No. 6, pp. 411-424.

Bianchini, A. (2018), "3PL provider selection by AHP and TOPSIS methodology", Benchmarking: An International Journal, Vol. 25 No. 1, pp. 235-252

Buttimer, R. J. Jr., Rutherford, R. C. and Witten, R. (1997), "Industrial Warehouse Rent Determinants in the Dallas/Fort Worth Area," Journal of Real Estate Research, Vol. 13 No. 1, pp. 4756.

BNP Paribas Real Estate (2018), European logistics market: property report Q4 2017.

Case, B. and Quigley, J. M. (1991), "The dynamics of real estate prices", The Review of Economics and Statistics, pp. 50-58.

Ciaramella, A. (2010), "The assessment of building performance: a property rating model for the office and logistic buildings", Proceeding of the European real estate conference, pp. 1-19.

Colicchia, C. and Strozzi, F. (2012), "Supply chain risk management: A new methodology for a systematic literature review", Supply Chain Management: An International Journal, Vol. 17 No. 4, pp. 403-418.

Coval, J., Jurek, J. and Stafford, E. (2009), "The economics of structured finance", Journal of Economic Perspectives, Vol. 23 No. 1, pp. 3-25.

Dablanc, L. and Ross, C. (2012), "Atlanta: A mega logistics center in the Piedmont Atlantic Megaregion (PAM)", Journal of transport geography, Vol. 24, pp. 432-442.

Dalkey, N. and Helmer, O. (1963), “An experimental application of the Delphi method to the use of experts”, Management Science, Vol. 9 No. 3, pp. 458-467.

De Marco, A., Ruffa, S. and Mangano, G. (2010), "Strategic factors affecting warehouse maintenance costs", Journal of Facilities Management, Vol. 8 No. 2, pp. 104-113.

De Marco, A. and Mangano, G. (2011), "Relationship between logistic service and maintenance costs of warehouses", Facilities, Vol. 29 No. 9/10, pp. 411-421. 
Decreto Ministeriale, No. 74, Prestazioni di resistenza al fuoco delle costruzioni nelle attività soggette al controllo del Corpo nazionale dei vigili del fuoco, 2007

Ding, G. K. (2008), "Sustainable construction-The role of environmental assessment tools", Journal of environmental management, Vol. 86 No. 3, pp. 451-464.

Diziain, D., Taniguchi, E. and Dablanc, L. (2014), "Urban logistics by rail and waterways in France and Japan”, Procedia-Social and Behavioral Sciences, Vol. 125, pp. 159-170.

El-Haram, M. A. and Horner, M. W. (2002), "Factors affecting housing maintenance cost", Journal of Quality in maintenance Engineering, Vol. 8 No. 2, pp. 115-123.

Fahimnia, B., Sarkis, J. and Davarzani, H. (2015), “Green supply chain management: A review and bibliometric analysis”, International Journal of Production Economics, Vol. 162, pp. 101-114.

Flanagin, A. J., Metzger, M. J., Pure, R., Markov, A. and Hartsell, E. (2014), "Mitigating risk in ecommerce transactions: perceptions of information credibility and the role of user-generated ratings in product quality and purchase intention", Electronic Commerce Research, Vol. 14 No. 1, pp. 1-23.

French, N. (2004), “The valuation of specialised property: A review of valuation methods", Journal of Property Investment \& Finance, Vol. 22 No. 6, pp. 533-541.

French, N. and Gabrielli, L. (2004), “The uncertainty of valuation”, Journal of Property Investment \& Finance, Vol. 22 No. 6, pp. 484-500.

Ginevičius, R. and Zubrecovas, V. (2009), "Selection of the optimal real estate investment project basing on multiple criteria evaluation using stochastic dimensions", Journal of business economics and management, Vol. 10 No. 3, pp. 261-270.

Glumac, B., Qi, H. A. N., Smeets, J. and Schaefer, W. (2011), "Rethinking Brownfield Redevelopment Features through Fuzzy Delphi Method”, The Valuation Journal, Vol. 6 No. 1, pp. 126-147.

GVA Redilco (2018), Logistics Real Estate Market Report Italy H1 2018.

He, Y., Wang, J., Wu, Z., Hu, L., Xiong, Y. and Fan, W. (2002), "Smoke venting and fire safety in an industrial warehouse”, Fire Safety Journal, Vol. 37 No. 2, pp. 191-215.

Hesse, M. (2004), "Land for logistics: locational dynamics, real estate markets and political regulation of regional distribution complexes", Tijdschrift voor economische en sociale geografie, Vol. 95 No. 2, pp. 162-173.

Hummon, N.P. and Doreian, P. (1989), "Connectivity in a citation network: the development of DNA theory”, Social Networks, Vol. 11 No. 1, pp. 39-63.

Israeli, A. A. (2002), "Star rating and corporate affiliation: their influence on room price and performance of hotels in Israel”, International Journal of Hospitality Management, Vol. 21 No. 4, pp. $405-424$.

Kaklauskas, A., Zavadskas, E. K., Banaitis, A. and Šatkauskas, G. (2007), "Defining the utility and market value of a real estate: a multiple criteria approach", International Journal of Strategic Property Management, Vol. 11 No. 2, pp. 107-120.

Kefer, P., Milanovic, D. D., Misita, M. and Zunjic, A. (2016), "Fuzzy multicriteria ABC supplier classification in global supply chain", Mathematical Problems in Engineering, Vol. 2016 No. 11, pp $1-12$.

Kreng, V. B. and Chen, F. T. (2008), "The benefits of a cross-docking delivery strategy: a supply chain collaboration approach", Production Planning and Control, Vol. 19 No. 3, pp. 229-241. 
Levitt, S. D. and Syverson, C. (2008), "Market distortions when agents are better informed: The value of information in real estate transactions", The Review of Economics and Statistics, Vol. 90 No. 4, pp. 599-611.

Lipińska-Słota, A. and Mindur, M. (2018), “The Future of the European Logistics Centres as Nodal Objects of Intermodal Transport Infrastructure”, Logistics and Transport, Vol. 38, pp. 41-58.

Ma, Y., Zhang, Z., Ihler, A. and Pan, B. (2018), "Estimating Warehouse Rental Price using Machine Learning Techniques”, International Journal of Computers, Communications \& Control, Vol. 13 No. 2, pp. 235-250.

Mangiaracina, R., Perego, A., Perotti, S. and Tumino, A. (2016), "Assessing the environmental impact of logistics in online and offline B2c purchasing processes in the apparel industry", International Journal of Logistics Systems and Management, Vol. 23 No. 1, pp. 98-124.

Mannion, R., Davies, H. T. and Marshall, M. N. (2005), "Cultural characteristics of "high" and "low" performing hospitals", Journal of health organization and management, Vol. 19 No. 6, pp. 431439.

Marsh, J. R., Green, K. W. and Dong, T. (1996), "Standardizing environmental assessments: a practical perspective”, Journal of environmental engineering, Vol. 122 No. 3, pp. 222-226.

Mattarocci, G. and Pekdemir, D. (2017), Logistic Real Estate Investment and REITs in Europe, Palgrave Macmillan, Cham.

Mattoni, B., Guattari, C., Evangelisti, L., Bisegna, F., Gori, P. and Asdrubali, F. (2018), “Critical review and methodological approach to evaluate the differences among international green building rating tools", Renewable and Sustainable Energy Reviews, Vol. 82, pp. 950- 960.

McKinnon, A. (2009), “The present and future land requirements of logistical activities", Land Use Policy, Vol. 26, pp. S293-S301.

Marchet, G., Melacini, M., Perotti, S., Tappia, E. (2015), "Incorporating the environmental dimension in the assessment of automated warehouses", Production Planning \& Control, Vol. 26 No. 10, pp. 824-838.

Ndour, B., Force, J. E. and McLaughlin, W. J. (1992), "Using the Delphi method for determining criteria in agroforestry research planning in developing countries", Agroforestry Systems, Vol. 19 No. 2, pp. 119-129.

Northcraft, G. B. and Neale, M. A. (1987), "Experts, amateurs, and real estate: An anchoring-andadjustment perspective on property pricing decisions", Organizational behavior and human decision processes, Vol. 39 No.1, pp. 84-97.

Oh, S. and Shin, J. (2016), "Logistics Warehouse Rent Determinants: Evidence from South Korea”, Information: an international interdisciplinary journal, Vol. 19 No. 10A, pp. 4405-4412.

Okoli, C. and Pawlowski, S. D. (2004), “The Delphi method as a research tool: an example, design considerations and applications", Information \& Management, Vol. 42 No. 1, pp. 15-29.

Oláh, J., Nestler, S., Nobel, T. and Popp, J. (2018), "International Characteristics of the MacroLogistics System of Freight Villages", Periodica Polytechnica Transportation Engineering, Vol. 43 No. 4, pp. 194-200.

Onstein, A. T., Ektesaby, M., Rezaei, J., Tavasszy, L. A., and Van Damme, D. A. (2019), "Importance of factors driving firms' decisions on spatial distribution structures", International Journal of Logistics Research and Applications, pp. 1-20. 
Pagourtzi, E., Assimakopoulos, V., Hatzichristos, T. and French, N. (2003), "Real estate appraisal: a review of valuation methods", Journal of Property Investment \& Finance, Vol. 21 No. 4, pp. 383401.

Pivo, G. (2008), "Responsible property investment criteria developed using the Delphi Method", Building Research \& Information, Vol. 36 No. 1, pp. 20-36.

Raut, R., Kharat, M., Kamble, S. and Kumar, C. S. (2018), "Sustainable evaluation and selection of potential third-party logistics (3PL) providers: An integrated MCDM approach", Benchmarking: An International Journal, Vol. 25 No. 1, pp. 76-97.

Renigier-Biłozor, M., Wisniewski, R., Kaklauskas, A. and Biłozor, A. (2014), "Rating methodology for real estate markets-Poland case study", International Journal of strategic property management, Vol. 18 No.2, pp. 198-212.

Ries, J. M., Grosse, E. H., and Fichtinger, J. (2017), "Environmental impact of warehousing: a scenario analysis for the United States", International Journal of Production Research, Vol. 55 No. 21, pp. 6485-6499.

Rousseau, D.M., Manning, J. and Denyer, D. (2008), "Evidence in management and organizational science: assembling the field's full weight of scientific knowledge through syntheses", The Academy of Management Annals, Vol. 2 No. 1, pp. 475-515.

Rouwenhorst, B., Reuter, B., Stockrahm, V., van Houtum, G. J., Mantel, R. J., and Zijm, W. H. (2000), "Warehouse design and control: Framework and literature review", European journal of operational research, Vol. 122 No. 3, pp. 515-533.

Sparling, E. I. and Sen, S. (2011, October), “Rating: how difficult is it?”, In Proceedings of the fifth ACM conference on Recommender systems, pp. 149-156.

Staudt, F. H., Alpan, G., Di Mascolo, M. and Rodriguez, C. M. T. (2015), "Warehouse performance measurement: a literature review", International Journal of Production Research, Vol. 53 No. 18, pp. 5524-5544.

Strozzi, F., Colicchia, C., Creazza, A. and Noè, C. (2017), "Literature review on the 'Smart Factory' concept using bibliometric tools", International Journal of Production Research, Vol. 55 No. 22, pp. 6572-6591.

Todd, J. A., Pyke, C. and Tufts, R. (2013), "Implications of trends in LEED usage: rating system design and market transformation", Building Research \& Information, Vol. 41 No. 4, pp. 384-400.

Tranfield, D., Denyer, D. and Smart, P. (2003), “Towards a methodology for developing evidenceinformed management knowledge by means of systematic review", British Journal of Management, Vol. 14 No. 3, pp. 207-22.

Turskis, Z., Zavadskas, E. K. and Peldschus, F. (2009), "Multi-criteria optimization system for decision making in construction design and management", Engineering economics, Vol. 6 No. 1.

Ugwu, O. O. and Haupt, T. C. (2007), "Key performance indicators and assessment methods for infrastructure sustainability-a South African construction industry perspective", Building and Environment, Vol. 42 No. 2, pp. 665-680.

Vieira, J. G. V., Toso, M. R., da Silva, J. E. A. R., and Ribeiro, P. C. C. (2017), "An AHP-based framework for logistics operations in distribution centres", International Journal of Production Economics, Vol. 187, pp. 246-259.

Villena, V. H. (2019), “The Missing Link? The Strategic Role of Procurement in Building Sustainable Supply Networks”, Production and Operations Management, Vol. 28 No. 5, pp. 1149-1172. 
Woudsma, C., Jensen, J. F., Kanaroglou, P. and Maoh, H. (2008), "Logistics land use and the city: A spatial-temporal modeling approach", Transportation Research Part E: Logistics and Transportation Review, Vol. 44 No. 2, pp. 277-297.

Wyman, D., Seldin, M. and Worzala, E. (2011), “A new paradigm for real estate valuation?”, Journal of Property Investment \& Finance, Vol. 29 No. 4/5, pp. 341-358.

Zimmermann, M., Althaus, H. J. and Haas, A. (2005), "Benchmarks for sustainable construction: A contribution to develop a standard", Energy and Buildings, Vol. 37 No.11, pp. 1147-1157. 